\title{
Role of Valgus Osteotomy in Intracapsular Fracture of Femur Neck
}

\author{
${ }^{1}$ Dr. K. V. Ramana Kumar, ${ }^{2}$ Dr. Sunil Kumar P \\ ${ }^{1,2}$ Assistant Professor in Orthopaedics Konaseema Institute Of Medical Sciences and Research
}

\begin{abstract}
The hip joint is a multi axial, ball and socket type of joint composed of head of the femur articulating with cup shaped fossa of acetabulum. An attempt has made in this study to evaluate the role of valgus osteotomy in the treatment of femur neck fractures. This was two year prospective study, consisting of 30 consecutive cases of femoral neck fractures treated by valgus osteotomy. Out of 240 intracapsular femoral neck fractures 30 cases were treated by valgus osteotomy in the orthopedic department. 19 (73\%) cases showed excellent results, 03 (12\%) cases showed good results and remaining 04 cases showed poor results. In summary, the concept of the Pauwels valgus osteotomy sees to be a valuable method of treating Pauwels type II and type III fractures and non unions of femoral neck in which the head is viable and the neck is fairly well preserved, in patients under 60 years of age.
\end{abstract}

Key Words: Femur neck fractures, Hip joint, Valgus osteotomy.

\section{Introduction:}

Fractures of femur neck, though they follow a very trivial trauma some times, have always presented great challenges to orthopedic surgeons and remained in many ways the unsolved fracture (1) as far as treatment and results are concerned. $10-15 \%$ of patients will develop complications over which the surgeon has little or no control $(2,3)$. In 1867 Phillips introduced a technique for longitudinal and lateral traction to be used in the treatment of femoral neck fractures to eliminate shortening or other deformities. In 1876 Maxwell reported the successful use of Phillips technique. Surgeons frustrated with the problems of management of femoral neck fractures, in view of the high failure rate, subsequently turned to primary prosthetic replacement, which is gaining popularity. In 1970, Sir John Charnely introduced low friction total hip arthroplastic, improving results with total hip replacement have let some to recommend its use in certain femoral neck fracture cases primarily $(4,5)$

An attempt has made in this study to evaluate the role of valgus osteotomy in the treatment of femur neck fractures. This is two year prospective study.

\section{Material And Methods:}

This was a two year prospective study, consisting of 30 consecutive cases of femoral neck fractures treated by valgus osteotomy.

Inclusion criterion:

- Patient below 60 years of age with history of femoral neck fracture

Exclusion criterion:

- $\quad$ Above 60 years of age

- Patients whose general condition is not good

- Patients with genuvalgus or foot deformitive or spinal abnormality.

Technique of operation:

The upper end of femur is exposed through the Watson Jones approach. Through an appropriately placed entry point on the lateral cortex the guide wire is passed into the neck and head of the femur at an appropriate angle with the help of angle guide under the image intensifier. $10-15 \mathrm{~mm}$ below the entry point an appropriate laterally based wedge of bone is removed, preferably at the inter-trochanteric level, with the help of drill bit and osteotome. The osteotomised fragements are approximated by abducting the limb and then a dynamic hip screw and plate are fixed. Post operatively the patient was followed up.

\section{Results:}

Out of 240 intracapsular femoral neck fractures 30 cases were treated by valgus osteotomy in the orthopedic department.

The nature of injury among 30 cases was shown in Table I. 
Table I

\begin{tabular}{|c|c|c|}
\hline TYPE OF INJURY & NO. OF CASES & PERCENTAGE \\
\hline ROAD TRAFFIC ACCIDENTS & 07 & 23 \\
\hline FALL DUE TO SLIP & 12 & 40 \\
\hline FALL FROM CYCLE/BIKE & 05 & 16.7 \\
\hline FALL FROM HEIGHT & 05 & 16.7 \\
\hline BUFFALO HIT & 01 & 3.3 \\
\hline
\end{tabular}

Valgus osteotomy was done for intracapsular femoral neck fracture between 15 years and 55 years in this study. The average age was 35.6 years. The age wise distribution of cases were shown in Table II

Table II

\begin{tabular}{|c|c|c|}
\hline Age in years & No. of cases & Percentage \\
\hline $15-25$ & 06 & 20 \\
\hline $26-35$ & 11 & 37 \\
\hline $36-45$ & 07 & 23 \\
\hline $46-55$ & 06 & 20 \\
\hline
\end{tabular}

Out of 30 cases 28 were males and 2 were females. Higher incidences of fractures are seen in males which are due to greater involvement in physical activity and more prone for RTA and fall from height.

For all the 30 cases radiological examination to assess the progress of union of osteotomy and fracture site was done regularly. 04 cases the follow up was missed and remaining 26 cases showed union of osteotomy in 6 weeks on average and fracture union was seen in an average of 12 weeks.

Table III shows the criterion for assessment of results

\begin{tabular}{|c|c|c|c|}
\hline RESULT & CLINCAL GRADING & RADIOLOGICAL GRADING & COMPLICATIONS \\
\hline Excellent & $\begin{array}{c}\text { no pain } \\
\text { no limp } \\
\text { full range of movements } \\
\text { quick return to work within 3- } \\
\text { 6months }\end{array}$ & $\begin{array}{l}\text { union of fracture in perfect } \\
\text { position } \\
\text { no evidence of avascular } \\
\text { necrosis }\end{array}$ & NIL \\
\hline Good & $\begin{array}{c}\text { No pain/bearable } \\
\text { Mild discomfort } \\
\text { Return to work with in 6-9 } \\
\text { months }\end{array}$ & $\begin{array}{c}\text { Union of fracture in good } \\
\text { position } \\
\text { No evidence of avascular } \\
\text { necrosis }\end{array}$ & Minimal \\
\hline Fair & $\begin{array}{c}\text { Moderate pain } \\
\text { Limitation of movements } \\
\text { walking with stick } \\
\text { Much delay in returning to } \\
\text { work (1 year) }\end{array}$ & $\begin{array}{l}\text { Union of fracture in good } \\
\text { position } \\
\text { Mottling and mild narrowing of } \\
\text { joint space }\end{array}$ & Moderate \\
\hline Poor & $\begin{array}{c}\text { Unbearable pain } \\
\text { Gross restriction of movements }\end{array}$ & $\begin{array}{l}\text { Non union } \\
\text { Implant failure }\end{array}$ & Infection \\
\hline
\end{tabular}

$19(73 \%)$ cases showed excellent results, $03(12 \%)$ cases showed good results and remaining 04 cases showed poor results.

\section{Discussion:}

The present study the average age was 35.6years, the male: female ratio being 14:1. Of the 30 cases taken up for study, four cases were lost for follow up. The history of having slipped and fallen down was the commonest mode of injury. Fracture sustained in road traffic accident are due to fall from height were more comminuted and associated with other injuries.

Osteotomy has come to the forefront of attention in treatment of intra trocantric femur neck fractures. It has been described for many different indications. It results in a change in configuration which results from the alteration in the axial alignment between the osteotomised fragments resulting in a change in the mechanical axis along which stress is transmitted from upper to the lower end of the bone. At the upper end of the femur such axial changes acquire special significance not only because of their anatomic effect on the involved femur but probably much more importantly because of their kinesiologic effect on the pelvis and through the pelvis on the opposite unaffected femur (6-9).

Based on theoretical aspects (10) Pauwels could demonstrate in 1935 that the healing process of femur neck fractures was influenced for more by biomechanical than biological factors. However, Pauwels principles contribute greatly to the understanding of non union of the femoral neck and its treatment by high femoral osteotomy. The therapeutically convincing concept of Pauwels was used in Europe. 
Postoperative period was uneventful in all patients. Early mobilization minimized the morbidity. All our patients were discharged with the advice of foot touchdown crutch walking. At follow up, patients were assessed clinically and radiologically. Six weeks later majority were advised partial weight bearing and range of motion exercises. Crutches were used until good bony union was demonstrated on the roentgenogram which usually took twelve weeks, while the osteotomy united in an average of six weeks. Fracture site consolidated in 25 of 26 cases $(96.7 \%)$ followed up.

In this study, 14 cases $(47 \%)$ were fresh cases, included because they could not be expected to unite by osteosynthesis alone in view of inherent instability. In summary, the concept of the Pauwels valgus osteotomy sees to be a valuable method of treating Pauwels type II and type III fractures and non unions of femoral neck in which the head is viable and the neck is fairly well preserved, in patients under 60 years of age.

To conclude valgus osteotomy, shifts the line of weight bearing axis of the extremity medially; minimizes the detrimental sharing forces and converts them into compressive forces by altering the fracture line from vertical to horizontal; positioning trocanter more satisfactorily reestablishes the function of the abductors more effectively, preserving the joint stability with uncompromised mobility; improves the gait by virtue of functional lengthening of the limb

\section{References:}

[1]. Dickson J. A. the unsolved fracture JBJS, 1953; 35: 805-22

[2]. Campbell's operative orthopaedics. $8^{\text {th }}$ ed. $1992 ; 929-43$.

[3]. Catto. M. A histological study of avascular necrosis of the femoral head after intracapsular fracture. JBJS. 1965; 47: 749-76.

[4]. Sim F H, Stauffer R N. management of hip fractures by total hip orthroplasty. Clin. Orthop. 1980; 152: $191-97$.

[5]. Smith F B. effects of rotary and valgus malpositions of blood supply to the femoral head. JBJS 1959; 41: 800-15.

[6]. Henrey M. osteotomy at the upper end of the femur. 1965; 106: 1-3.

[7]. King T. The closed operation for intracapsular fractures of the neck of the femur. JBJS.1938; 26: 721-48

[8]. Leadbetter G W. cervical axial osteotomy of the femur. JBJS 1944; 26: 713

[9]. Linton P. types of displacement in fractures of the neck of the femur. JBJS. 1949; 31: 184-89.

[10]. Ballmer F T, Ballmer P M. Pauwels osteotomy for non union of the femoral neck. 1990. 